\title{
Development of a Die Material for Isothermal Forging of Superalloys in Air*
}

\author{
By Takehiro OHNO,** Rikizo WATANABE** and Toshiaki NONOMURA ${ }^{* * *}$
}

\begin{abstract}
Synopsis
In isothermal forging, since the die is heated as well as the workpiece, high-temperature strength is essentially required for the die material. In particular, isothermal forging of superalloys is carried out at high temperature ranging $1000 \sim 1100^{\circ} \mathrm{C}$, thus a molybdenum-base alloy, TZM, is generally used as a die material. Although TZM has good high-temperature strength, its oxidation resistance is very poor at above $600^{\circ} \mathrm{C}$, therefore, forging must be done in vacuum or inert-gas atmosphere.

If there is a die material having both enough strength and oxidation resistance at around $1000 \sim 1100^{\circ} \mathrm{C}$, isothermal forging of superalloys in air will be possible, and the forging apparatus will be simpler.

To develop such a die material, the authors directed their attention to chromium free nickel-base cast alloys, because such alloys are able to contain a large amount of heavy metals such as molybdenum and tungsten, as being soluble in $\gamma$ and $\gamma^{\prime}$ instead of chromium, and are expected to have higher strength at above $1000^{\circ} \mathrm{C}$.

Several conventional and experimental alloys were investigated. From the results of compression, compressive creep and oxidation resistance tests, "Nimowal" (Ni-10Mo-12W-6Al-0.01Y) showed the best properties as a whole. Its short-time strength is equivalent to that of Mar-M200 at $950 \sim 1000^{\circ} \mathrm{C}$, higher than that of Mar-M200 and equivalent to that of TZM at $1050 \sim 1100^{\circ} \mathrm{C}$. Its compressive creep strength is higher than that of Mar-M200 at $1000 \sim 1100^{\circ} \mathrm{C}$. Oxidation resistance of Nimowal is equivalent to that of Mar-M200 and enough to be used in air. Moreover, Nimowal has better machinability than MarM200.

Simulation tests of isothermal forging of superalloys in air were made with Nimowal being used as the die material. One-tenth model disk of In-100 was successfully forged from the extruded billet without any damage or significant oxidation of the die.
\end{abstract}

Key words: die for isothermal forging; nickel-base cast alloy; high-temperature strength; oxidation resistance; intermetallic compound.

\section{Introduction}

Isothermal forging in which the die and the workpiece temperatures are the same and the strain rate is controlled has several advantages compared with conventional forging, that is, (1) materials with poor hot workability and products with complex configuration can be forged; (2) the capacity of the forging press can be relatively small; (3) the weight of forging stock can be reduced, because forging to near net shape is possible; (4) the microstructures of products are uniform and the mechanical properties are stable. From these advantages, isothermal forging is applied mainly to produce the aircraft engine parts of titanium alloys and superalloys. In particular, turbine engine disks made of powder superalloys such as IN-100, cannot be commercially produced without isothermal forging process.

In isothermal forging, since the die is heated as well as the workpiece, the die material with hightemperature strength is required. Nickel-base alloys such as IN-100 or Mar-M200 are used as die materials for the isothermal forging of titanium alloys, because the forging temperature is below $1000^{\circ} \mathrm{C}$. On the other hand, the forging temperature of nickel-base superalloys is so high ranging $1000 \sim 1100^{\circ} \mathrm{C}$, that TZM, a molybdenum-base alloy, is generally used as a die material.

TZM has good high-temperature strength, but its oxidation resistance is very poor at above $600^{\circ} \mathrm{G}$. Therefore forging must be done in vacuum or inertgas atmosphere and the vacuum chamber surrounding the die set is necessary, which makes the forging apparatus complicated. If there is a die material having both enough strength and oxidation resistance at around $1000 \sim 1100^{\circ} \mathrm{C}$, isothermal forging of superalloys in air will be possible. Thus the forging apparatus will be simpler and the forging practice will be more efficient.

Based on the above idea, the authors tried to develop a new die material which can be used in air. The authors directed their attention to chromium free nickel-base cast alloys. First, the properties of conventional alloys were evaluated as die materials, secondly experimental alloys were investigated to develop a new material.

\section{Experimental Procedures}

In order to evaluate the properties of alloys as die materials for isothermal forging in air, compression tests, compressive creep tests and oxidation resistance tests at high-temperature were carried out. Machinability tests were also done on some alloys.

The specimens of nickel-base alloys were machined from $10 \mathrm{~kg}$ ingots cast in air. No heat treatments were done. The specimens of TZM were machined from a commercial round bar of $22 \mathrm{~mm}$ diameter.

Compression tests were carried out by an electrohydraulic servo testing machine with an induction heater with cylindrical specimens of $10 \mathrm{~mm}$ diameter and $12 \mathrm{~mm}$ length. Specimens were compressed by $10 \%$ with the strain rate of $10^{-3} / \mathrm{s}$ and at the temperatures of $950,1000,1050$ and $1100^{\circ} \mathrm{C}$, and the compressive yield strengths were measured. These

* Originally published in Press Working, 24 (1986), No. 4, 106, in Japanese; formerly presented to the 110th ISIJ Meeting, October 1985, S1548, at Niigata University in Niigata. English version received on April 22, 1986; accepted in the final form on September 12, 1986. (C) 1987 ISIJ

** Metallurgical Laboratory, Yasugi Works, Hitachi Metals, Ltd., Yasugi-cho, Yasugi 692.

*** Material and Process Engineering Dept., Yasugi Works, Hitachi Metals, Ltd., Yasugi-cho, Yasugi 692. 
tests were done in air for nickel-base alloys and in vacuum for TZM.

Compressive creep tests were carried out either by the electro-hydraulic servo testing machine or by a compressive creep testing apparatus modified from a stress rupture testing apparatus with cylindrical specimens of $10 \mathrm{~mm}$ or $8 \mathrm{~mm}$ diameter and $10 \mathrm{~mm}$ length. Specimens were maintained under constant compressive loads at constant temperatures. The compressive creep strains after $20 \mathrm{~h}$ or the time to $10 \%$ creep strain were measured.

Oxidation resistance tests were carried out with cylindrical specimens of $10 \mathrm{~mm}$ diameter and $20 \mathrm{~mm}$ length. It was repeated ten times to heat the specimens for $16 \mathrm{~h}$ at $1100^{\circ} \mathrm{G}$ in air, and each oxidation loss was measured.

Machinabilities were evaluated by turning tests and drilling tests. Turning tests were carried out with two kinds of tips, carbide tips equivalent to K20 and TiGN coated carbide tips. The turning conditions will be shown later in Fig. 8. Machinabilities were evaluated by measuring flank wears of the tools after $5 \mathrm{~min}$ turning. Drilling tests were carried out with $8 \mathrm{~mm}$ diameter carbide drills. The drilling conditions will be shown later in Fig. 9. The time to drill the specimen to $10 \mathrm{~mm}$ depth under constant load was measured, which was repeated untill the total time reached to $30 \mathrm{~min}$. Machinabilities were evaluated by the total depth at $30 \mathrm{~min}$.

Physical properties were measured as follows. Melting and solidification temperatures were measured by a high-temperature differential thermal analyzer. Specific heat and thermal conductivity were measured by a laser flash type thermal constant analyzer. Mean coefficients of thermal expansion were measured by a dilatometer.

The simulation tests of isothermal forging in air were made, with the developed alloy being used as the die material. Experimental procedures will be shown later in Sec. III. 4 together with experimental results.

\section{Results and Discussion}

\section{Evaluation of Conventional Alloys}

One of the materials which has possibility to obtain both good oxidation resistance and high-temperature strength comparable to those of molybdenum-base alloys is nickel-base cast alloys. However, even for the strongest ordinary type nickel-base alloys such as Mar-M200, high-temperature strength at above $1000^{\circ} \mathrm{C}$ is far less than that of molybdenum-base alloys.

Thus, special type alloys which contain no chromium were given much attention, because such alloys are able to contain a large amount of heavy metals such as molybdenum and tungsten, as being soluble in $\gamma$ and $\gamma^{\prime}$ instead of chromium, and are expected to have higher strength at above $1000^{\circ} \mathrm{C}$. There are a few such type alloys known, for example, NX-188, ${ }^{1)}$ developed as a cast alloy and RSR-185,2) developed as a rapid solidification alloy. However, no example is found that these alloys were used as die materials.

Therefore, NX-188 and RSR-185 were evaluated as die materials, compared to a typical nickel-base alloy, Mar-M200 and a molybdenum-base alloy, TZM, Table 1 shows the chemical compositions of the specimens of these alloys. Mar-M200 contains eight elements other than chromium. On the other hand, both NX-188 and RSR-185 consist of rather simple compositions, NX-188 containing only molybdenum and aluminum, RSR-185 containing only molybdenum, aluminum and tungsten.

The results of the evaluation tests are shown in Figs. 1 to 3. "Nimowal", shown in these figures is the developed alloy which will be described later.

Figure 1 shows compressive yield strengths of these alloys at $950 \sim 1100^{\circ} \mathrm{C}$ and tensile strengths of $\mathrm{TZM}$ cited from Refs. 3) and 4). The strength levels of TZM vary to some extent in these three data, probably because of the difference of the manufacturing processes. However, these data show the same tendency, that is, the tensile strength and the compressive yield strength of TZM are not so high at around $950^{\circ} \mathrm{C}$, but do not decrease so much at higher temperature. On the other hand, the compressive yield strength of Mar-M200 is high at below $1000^{\circ} \mathrm{C}$, but decreases rapidly at above $1000^{\circ} \mathrm{C}$. The high-temperature strengths of NX-188 and RSR-185 are close to that of TZM. They are considerably higher than that of Mar-M200, but slightly lower than the average high-temperature strength of TZM at $1050 \sim$ $1150^{\circ} \mathrm{C}$.

Oxidation resistances of these alloys are shown in Fig. 2. Mar-M200 shows the best oxidation resistance among these three alloys. However, the oxidation losses of NX-188 and RSR-185 are not so much, for example, the oxidation loss of RSR-185 after 10 cycles is only about $6 \mu \mathrm{m}$ converted to the oxidation thickness, that is thought to be small enough to be used as a die material for isothermal forging in air.

Figure 3 shows compressive creep strengths of NX188, RSR-185 and Mar-M200. Testing conditions are also shown in Fig. 3. The results reveal the similar tendency to those of compression tests, that is,

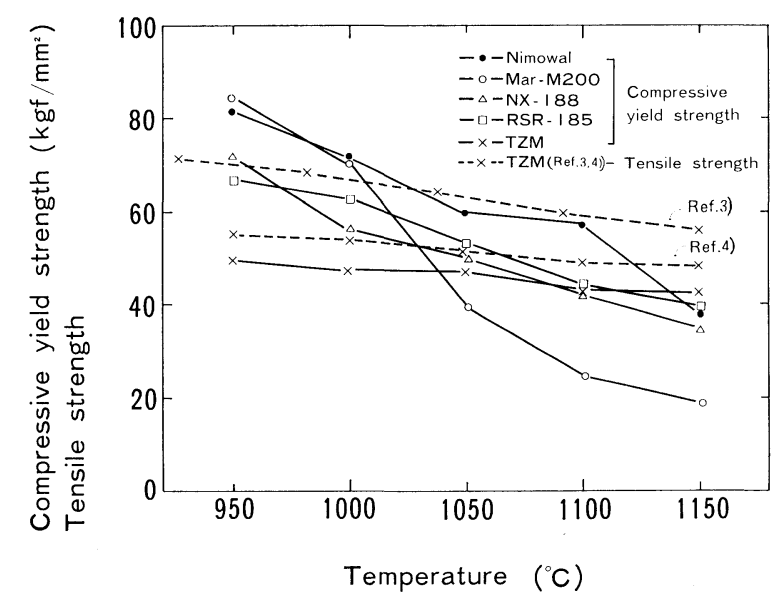

Fig. 1. Compressive yield strength or tensile strength of Nimowal, conventional nickel-base supreralloys and TZM. 
Table 1. Chemical compositions of the specimens of conventional nickel-base superalloys

\begin{tabular}{|c|c|c|c|c|c|c|c|c|c|c|c|c|c|}
\hline & $\mathrm{C}$ & $\mathrm{Si}$ & $\mathrm{Mn}$ & $\mathrm{P}$ & $\mathrm{S}$ & $\mathrm{Cr}$ & Co & W & Mo & $\mathrm{Al}$ & $\mathrm{Ti}$ & $\mathrm{Nb}$ & $\mathrm{Fe}$ \\
\hline Mar-M200 & 0.14 & 0.11 & 0.02 & 0.001 & 0.003 & 8.56 & 9.80 & 11.76 & 0.29 & 5.08 & 2.23 & 1.05 & - \\
\hline NX-188 & 0.007 & 0.08 & $<0.01$ & 0.003 & 0.004 & 0.16 & - & - & 17.70 & 7.40 & - & - & - \\
\hline RSR-185 & 0.009 & 0.08 & $<0.01$ & 0.002 & 0.001 & 0.01 & $<0.01$ & 5.88 & 13.92 & 7.06 & - & - & - \\
\hline TZM & 0.02 & $<0.01$ & - & - & - & - & - & - & Bal & - & 0.50 & - & 0.01 \\
\hline
\end{tabular}

Table 2. Chemical compositions of the specimens of experimental alloys. (wt\%)

\begin{tabular}{cccccccccccc}
\hline Alloy & $\mathrm{G}$ & $\mathrm{Si}$ & $\mathrm{Mn}$ & $\mathrm{P}$ & $\mathrm{S}$ & $\mathrm{W}$ & $\mathrm{Mo}$ & $\mathrm{Ta}$ & $\mathrm{Al}$ & $\mathrm{Y}$ & $\mathrm{Ni}$ \\
\hline RA1 & 0.003 & 0.06 & 0.01 & 0.001 & 0.001 & 0.01 & 17.88 & - & 8.01 & 0.01 & $\mathrm{Bal}$ \\
RA2 & 0.003 & 0.03 & 0.01 & 0.002 & 0.001 & 5.93 & 14.12 & - & 7.01 & 0.01 & $\mathrm{Bal}$ \\
RA3 & 0.005 & 0.02 & 0.01 & 0.002 & 0.001 & 11.97 & 10.08 & - & 6.22 & 0.01 & $\mathrm{Bal}$ \\
RA4 & 0.002 & 0.02 & 0.01 & 0.001 & 0.001 & 17.77 & 6.10 & - & 5.08 & 0.01 & $\mathrm{Bal}$ \\
RA5 & 0.002 & 0.01 & 0.01 & 0.001 & 0.001 & 5.76 & 9.94 & 5.80 & 5.00 & 0.01 & $\mathrm{Bal}$ \\
RA6 & 0.002 & 0.01 & 0.01 & 0.001 & 0.001 & 0.09 & 13.96 & 5.83 & 6.11 & 0.01 & $\mathrm{Bal}$ \\
\hline
\end{tabular}

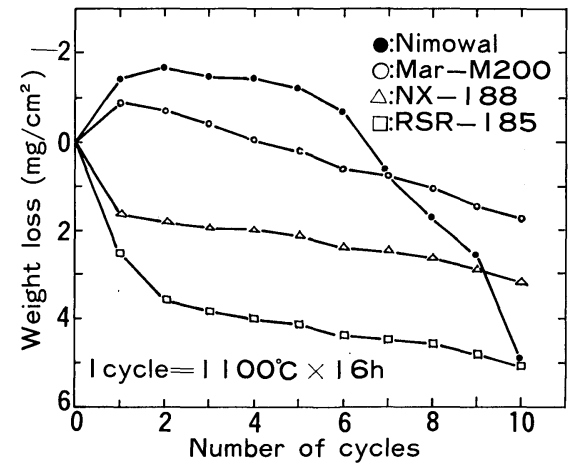

Fig. 2. Oxidation resistance of Nimowal and conventional nickel-base superalloys.

the compressive creep strengths of NX-188 and RSR185 are lower than that of Mar-M200 at $1000^{\circ} \mathrm{C}$, but higher at 1050 and $1100^{\circ} \mathrm{C}$. In particular, Mar-M200 shows extremely large creep strain at $1100^{\circ} \mathrm{C}$, while NX-188 and RSR-185 show only small creep strains.

From the above results, two chromium free alloys, NX-188 and RSR-185 are considered to be hopeful as die materials for isothermal forging in air, compared to ordinary type alloys containing chromium such as Mar-M200. However, their high-temperature strengths are slightly lower than the average strength of TZM. Thus, the authors tried to develop a new alloy which has better properties.

\section{Evaluation of Experimental Alloys}

In order to develop a new alloy which has better properties than NX-188 and RSR-185, the effects of the increase in tungsten content and the addition of tantalum to improve high-temperature strength and the addition of a small amount of yttrium to improve oxidation resistance were investigated. Six experimental alloys were selected and evaluated. The chemical compositions are shown in Table 2. RAl and RA2 were designed by adding yttrium to NX-188 and RSR-185, respectively. RA3 and RA4 were designed on the extension of the direction from RAl to RA2, namely, tungsten was increased by $6 \%$, molybdenum was decreased by $4 \%$ and aluminum

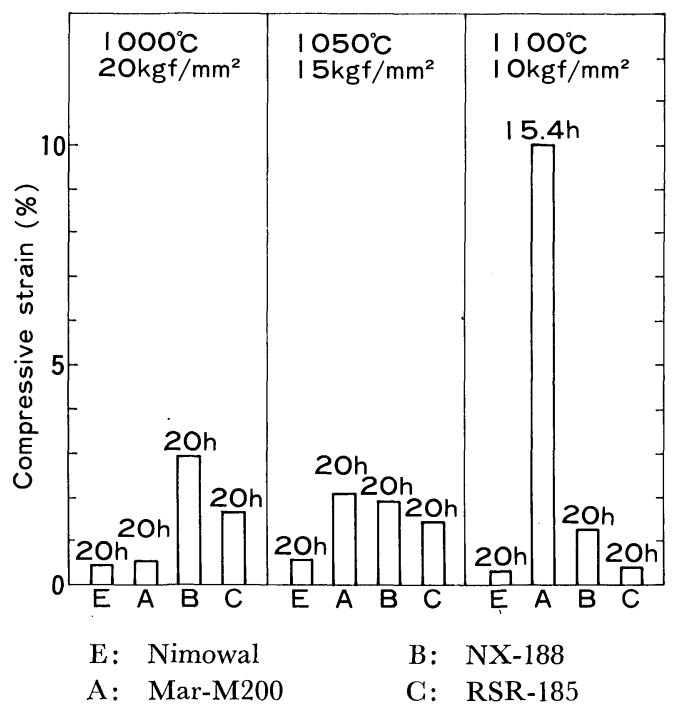

Fig. 3. Compressive creep strength of Nimowal and conventional nickel-base superalloys.

was decreased by $1 \%$, progressively. RA6 was designed by adding yttrium to MMT143, ${ }^{5)}$ which is known as a single crystal superalloy having high strength. By increasing tungsten and decreasing molybdenum and aluminum of RA6, RA5 was designed.

Figure 4 shows the compressive yield strengths of these alloys at $950 \sim 1150^{\circ} \mathrm{C}$. RA3 and RA4 show rather high strengths, which indicates that the increase in tungsten contributes to the increase in strength. On the other hand, the addition of tantalum does not affect so much the increase in strength as the increase in tungsten does. By the addition of yttrium, RAl shows lower strength than NX-188 and RA2 shows almost the same strength as RSR-185.

Oxidation resistances of these alloys are shown in Fig. 5. RA4, containing the largest amount of tungsten, shows extremely poor oxidation resistance compared with the other alloys, which indicates that too much tungsten is detrimental to oxidation resistance, although it is effective for strength. Another reason for the poor oxidation resistance of RA4 might be pointed out, that is, aluminum of RA4 is relatively 
and TZM. (wt\%)

\begin{tabular}{cccccc}
\hline $\mathrm{B}$ & $\mathrm{Zr}$ & $\mathrm{O}$ & $\mathrm{N}$ & $\mathrm{H}$ & $\mathrm{Ni}$ \\
\hline 0.015 & 0.10 & - & - & - & $\mathrm{Bal}$ \\
- & - & - & - & - & $\mathrm{Bal}$ \\
- & - & - & - & - & $\mathrm{Bal}$ \\
- & 0.09 & 0.0007 & 0.0005 & 0.0001 & 0.001 \\
\hline
\end{tabular}

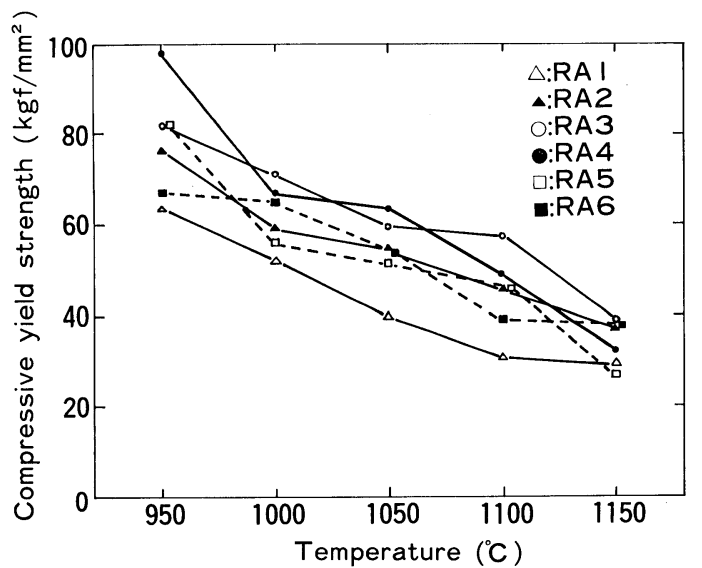

Fig. 4. Compressive yield strength of experimental alloys.

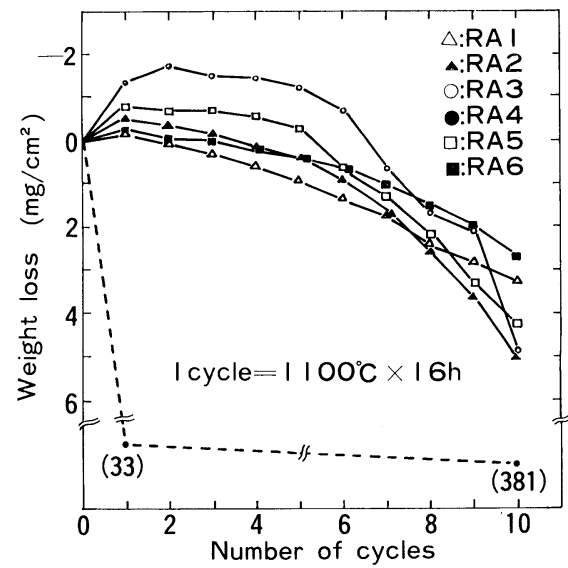

Fig. 5. Oxidation resistance of experimental alloys.

small. However, RA5, containing the same amount of aluminum as RA4, shows much better oxidation resistance than RA4, which suggests at least that tungsten is more detrimental to oxidation resistance than tantalum. Little difference of oxidation resistances among five alloys other than RA4 was observed. Oxidation resistances of these five alloys are found to be improved at the first several heating cycles, because of the small addition of yttrium.

Compressive creep tests (by the electro-hydraulic servo testing machine, specimen size: $10 \mathrm{~mm}$ dia. $\times$ $10 \mathrm{~mm}$ length) were carried out only on three alloys, RA2, RA3 and RA5, which showed both good compressive strengths and enough oxidation resistances. The testing conditions and the results are shown in Fig. 6. RA2 shows lower creep strength at 1000 and $1050^{\circ} \mathrm{G}$ than the others. Both RA3 and RA5 show good creep strengths. In particular, the creep strength of RA3 was highest. Thus, RA3, which

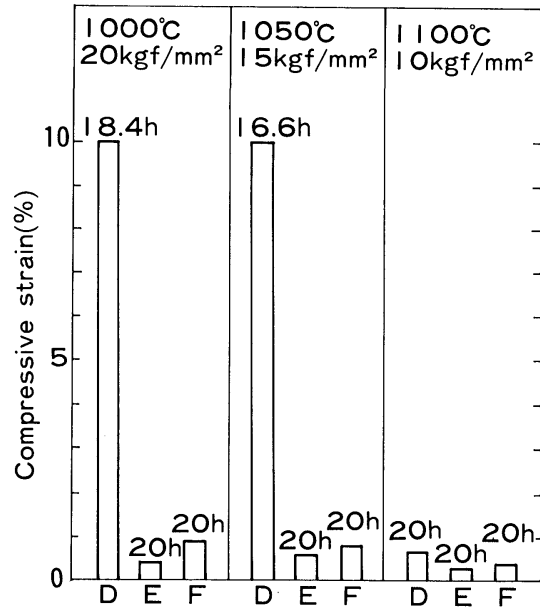

D: RA2 E: RA3 F: RA5

Fig. 6. Compressive creep strength of experimental alloys.

showed good properties throughout the above tests, was selected as the developed alloy and named "Nimowal" by fastening its main alloying elements, $\mathrm{Ni}-\mathrm{Mo}-\mathrm{W}-\mathrm{Al}$.

\section{The Properties of the Developed Alloy, Nimowal}

The properties of Nimowal will be shown in this section, compared with those of conventional nickelbase alloys, Mar-M200, NX-188 and RSR-185 and a molybdenum-base alloy, TZM.

Some results already obtained in previous sections were summarized in Figs. 1 to 3 . Figure 1 shows high-temperature strengths of Nimowal and the conventional nickel-base alloys and TZM. The compressive yield strength of Nimowal is equivalent to that of Mar-M200 at $950 \sim 1000^{\circ} \mathrm{C}$, much higher than that of Mar-M200 and equivalent to the tensile strength of TZM at $1050 \sim 1100^{\circ} \mathrm{C}$, moreover, constantly higher than those of NX-188 and RSR-185 at $950 \sim 1100^{\circ} \mathrm{C}$. Oxidation resistances of Nimowal and the conventional nickel-base alloys are shown in Fig. 2. The oxidation resistance of Nimowal is equivalent to that of Mar-M200 at least during seven heating cycles. Moreover, the oxidation loss after ten cycles is only about $6 \mu \mathrm{m}$ converted to the oxidation thickness, that is small enough for practical use. Figure 3 shows compressive creep strengths of Nimowal and conventional nickel-base alloys, indicating that Nimowal possesses the highest creep strength among these four alloys.

Some additional evaluation tests were carried out. Several heats of Nimowal and Mar-M200 were cast for these tests. Table 3 shows the chemical composition ranges of the specimens used in these tests.

To evaluate further compressive creep properties, Nimowal and Mar-M200 were tested by the modified creep testing apparatus under several compressive stresses at 1000,1050 and $1100^{\circ} \mathrm{C}$. The compressive creep strains after holding for $20 \mathrm{~h}$ were measured. The specimen size was $8 \mathrm{~mm}$ diameter and $10 \mathrm{~mm}$ length. In these test conditions, $20 \mathrm{~h}$ of holding time corresponds to the time to forge 100 products when a product is forged in $12 \mathrm{~min}$ 
Table 3. Chemical composition ranges of the specimens of Nimowal and Mar-M200. (wt\%)

\begin{tabular}{|c|c|c|c|c|c|c|c|c|c|c|c|c|c|c|c|c|}
\hline & G & $\mathrm{Si}$ & $\mathrm{Mn}$ & $P$ & $\mathrm{~S}$ & $\mathrm{Cr}$ & Co & W & Mo & $\mathrm{Al}$ & $\mathrm{Ti}$ & $\mathrm{Nb}$ & B & $\mathrm{Zr}$ & $\mathrm{Y}$ & $\mathrm{Ni}$ \\
\hline Nimowal & $\begin{array}{c}0.002 \\
\stackrel{?}{ } \\
0.013\end{array}$ & $\begin{array}{c}0.01 \\
? \\
0.10\end{array}$ & $\begin{array}{l}0.01 \\
? \\
0.08\end{array}$ & 0.001 & 0.001 & - & - & $\begin{array}{c}11.28 \\
11.60\end{array}$ & ${ }_{10.28}^{10.08}$ & $\begin{array}{l}6.00 \\
? \\
6.18\end{array}$ & - & - & - & - & 0.01 & Bal \\
\hline $\begin{array}{l}\text { Mar- } \\
\text { M200 }\end{array}$ & $\begin{array}{c}0.124 \\
\stackrel{2}{0.144}\end{array}$ & $\begin{array}{c}0.06 \\
\text { ? } \\
0.07\end{array}$ & $\begin{array}{c}0.01 \\
? \\
0.02\end{array}$ & $\begin{array}{c}0.001 \\
\text { l } \\
0.003\end{array}$ & $\begin{array}{c}0.002 \\
? \\
0.003\end{array}$ & $\begin{array}{l}8.67 \\
? \\
9.00\end{array}$ & $\begin{array}{c}9.87 \\
? \\
9.95\end{array}$ & ${ }_{11.69}^{11.26}$ & - & $\begin{array}{c}4.79 \\
? \\
5.12\end{array}$ & $\begin{array}{c}1.95 \\
? \\
1.96\end{array}$ & $\begin{array}{c}1.03 \\
2 \\
1.12\end{array}$ & $\begin{array}{c}0.016 \\
? \\
0.018\end{array}$ & $\begin{array}{c}0.06 \\
? \\
0.12\end{array}$ & - & $\mathrm{Bal}$ \\
\hline
\end{tabular}

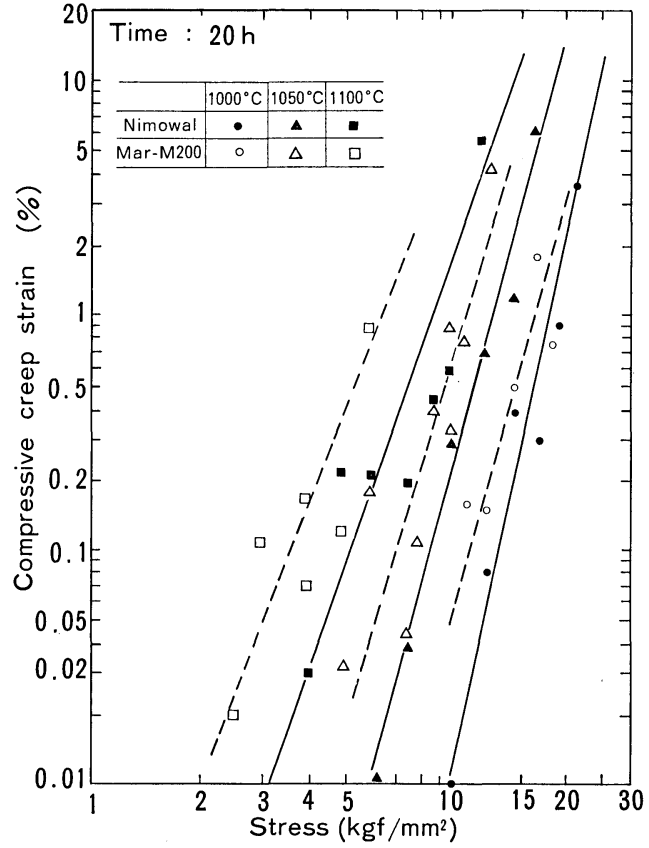

Fig. 7. 20h compressive creep strength of Nimowal and Mar-M200.

with the strain rate of $10^{-3} / \mathrm{s}$ and the reduction of $72 \%$. The results are shown in Fig. 7 with the stress as the abscissa and the strain as the ordinate. The compressive creep strength of Nimowal is higher than that of Mar-M200 at each temperature.

The compressive creep strengths of Nimowal and Mar-M200 at $20 \mathrm{~h}$ and $0.1 \%$ creep strain obtained from Fig. 7 are shown in Table 4 compared with the compressive yield strength of extruded $1 \mathrm{~N}-100$, a typical superalloy to which isothermal forging is applied. Since the compressive creep strength of Nimowal at $20 \mathrm{~h}$ and $0.1 \%$ strain is over three times larger than the compressive yield strength of $1 \mathrm{~N}$ 100 at $1000 \sim 1100^{\circ} \mathrm{C}$, isothermal forging under the above conditions is thought to be possible within the size accuracy of $0.1 \%$. On the other hand, the compressive creep strength of Mar-M200 is also higher than the compressive yield strength of $1 \mathrm{~N}-100$, but the difference comes to smaller as the temperature comes higher, especially at $1100^{\circ} \mathrm{C}$ where the compressive creep strength of Mar-M200 is only two times higher than the compressive yield strength of $1 \mathrm{~N}-100$. Therefore Mar-M200 might be deformed to an untolerable extent when used at high-temperature as a die material.

Machinability of Nimowal was compared with Mar-M200 by two kinds of tests, turning and drilling. Figure 8 shows the results obtained by turning tests,
Table 4. Compressive creep strength of Nimowal and Mar-M200, and compressive yield strength of as-extruded IN-100.

\begin{tabular}{lllll}
\hline \multicolumn{1}{c}{ Temperature $\left({ }^{\circ} \mathrm{C}\right)$} & & 1000 & 1050 & 1100 \\
\hline $\begin{array}{l}20 \mathrm{~h}, 0.1 \% \text { compressive creep } \\
\text { strength }\left(\mathrm{kgf} / \mathrm{mm}^{2}\right)\end{array}$ & Nimowal & 13.5 & 8.8 & 5.4 \\
& Mar-M200 & 11.3 & 7.1 & 3.7 \\
\hline $\begin{array}{l}\text { Compressive yield strength } \\
\text { with the strain rate of } \\
10^{-3} / \mathrm{s}\left(\mathrm{kgf} / \mathrm{mm}^{2}\right)\end{array}$ & $\begin{array}{l}\text { IN-100 } \\
\text { (Extruded) }\end{array}$ & 2.7 & 1.9 & 1.7 \\
\hline
\end{tabular}

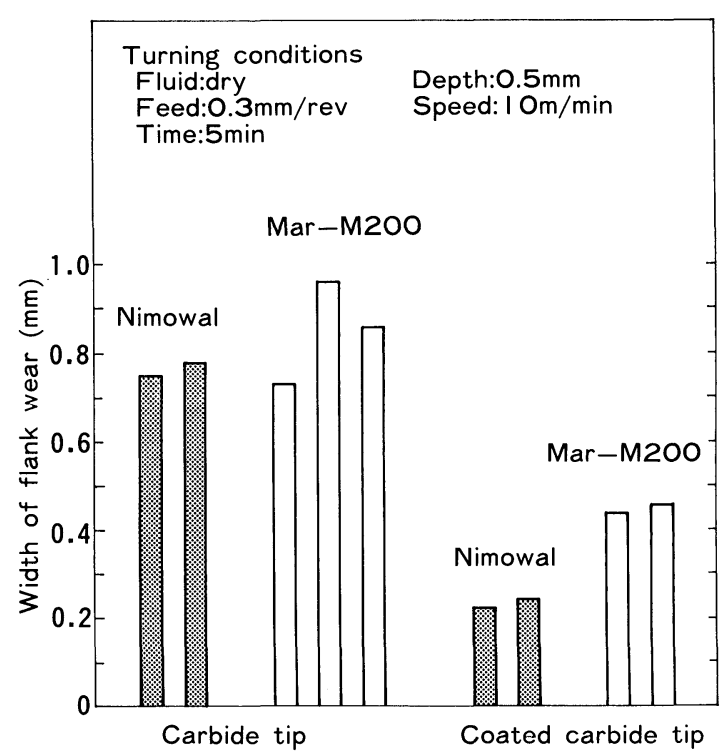

Fig. 8. Machinability of Nimowal and Mar-M200 by turining test.

indicating that Nimowal has better machinability than Mar-M200, especially when coated carbide tips were used. The results obtained by drilling tests are shown in Fig. 9. Machinability of Nimowal by drilling is over two times better than that of MarM200. It is obvious from the above results that Nimowal possesses better machinability than conventional nickel-base cast superalloys, which is advantageous to be practically used as a die material.

SEM microstructures and EDX analyses of Nimowal and Mar-M200 are shown in Fig. 10. Both alloys mainly consist of $\gamma$ and $\gamma^{\prime}$ but the coarse crystallized phases pointed by the arrows of A and B in Fig. 10 are completely different from each other. Phase A of Nimowal is $\alpha$-(Mo, W) which mainly consists of tungsten and molybdenum as indicated by EDX analysis. On the other hand, phase B of Mar-M200 is MC-type carbide which mainly consists of titanium, niobium and tungsten as indicated by EDX analysis. Since $\alpha-(\mathrm{Mo}, \mathrm{W})$ is much softer than carbide, such 


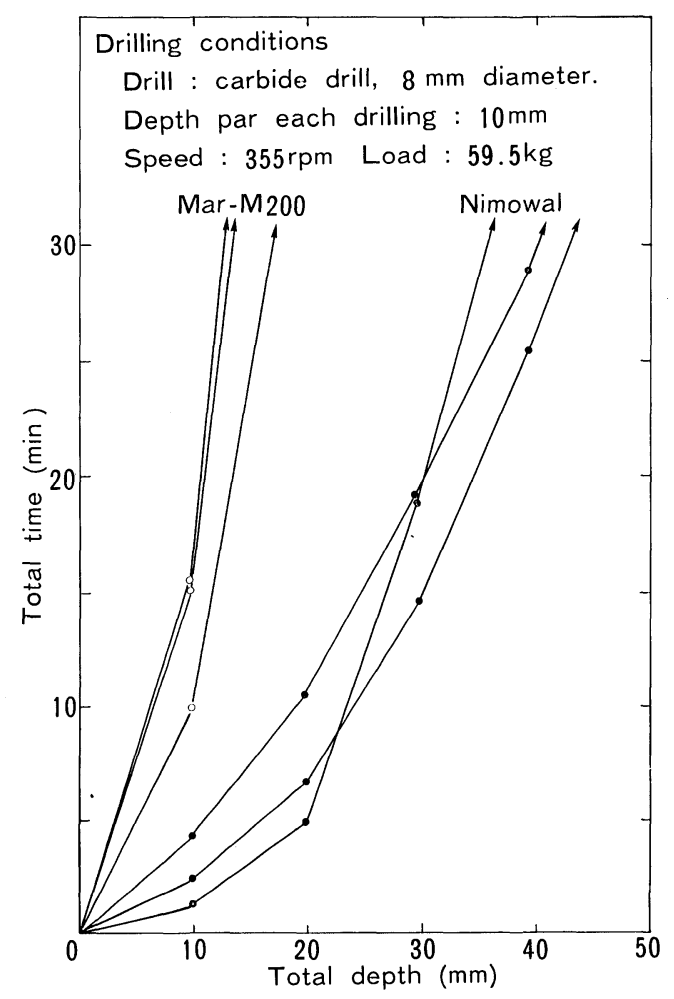

Fig. 9. Machinability of Nimowal and Mar-M200 by drilling test. a difference of the phases between Nimowal and Mar-M200 is considered to affect machinabilities of these alloys.

Figure 11 shows as-polished microstructures of Nimowal and Mar-M200. Many microporosities are observed in Mar-M200, while few ones in Nimowal. There exists an appreciable amount of eutectic $\gamma^{\prime}$ in Mar-M200, and microporosities are found along such eutectic $\gamma^{\prime}$. On the other hand, some grain boundaries of Nimowal are enveloped by $\alpha$-(Mo, W). Since $\alpha-(\mathrm{Mo}, \mathrm{W})$ is a bcc phase, it shrinks less than fcc $\gamma$ and $\gamma^{\prime}$ phases when solidifying. This is considered to contribute to the characteristic casting behavior of Nimowal that microporosities are hardly formed.

Figure 12 shows the mean coefficients of thermal expansion of Nimowal, the conventional nickel-base superalloys and TZM. The data of TZM was cited from Ref. 6). TZM has much lower mean coefficient of thermal expansion than the nickelbase alloys including Nimowal. The thermal expansion coefficient of Nimowal is equivalent to those of NX-188 and RSR-185 and slightly lower than that of Mar-M200. The mean coefficient of thermal expansion of Nimowal from 30 to $1050^{\circ} \mathrm{G}$ is equivalent to that of Mar-M200 from 30 to $900^{\circ} \mathrm{C}$. Since Mar-M200 is used as a die material at around $900^{\circ} \mathrm{C}$, this indicates that Nimowal can be practically used
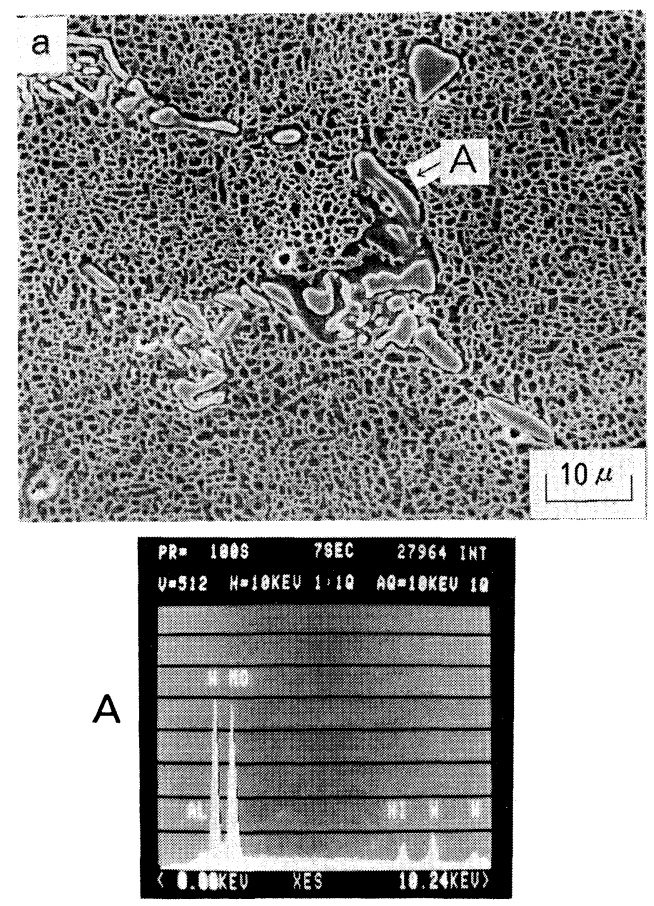
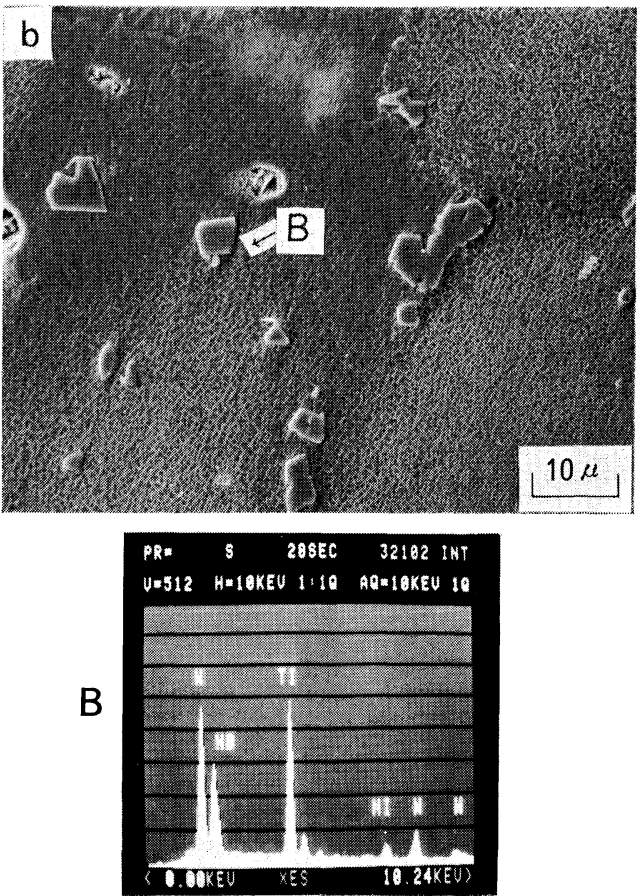

(a) Nimowal

(b) Mar-M200

Fig. 10.

SEM microstructure and EDX analysis of Nimowal and MarM200 (a) Nimowal
(b) Mar-M200

Fig. 11. Microstructure of Nimowal and MarM200 (no etching).
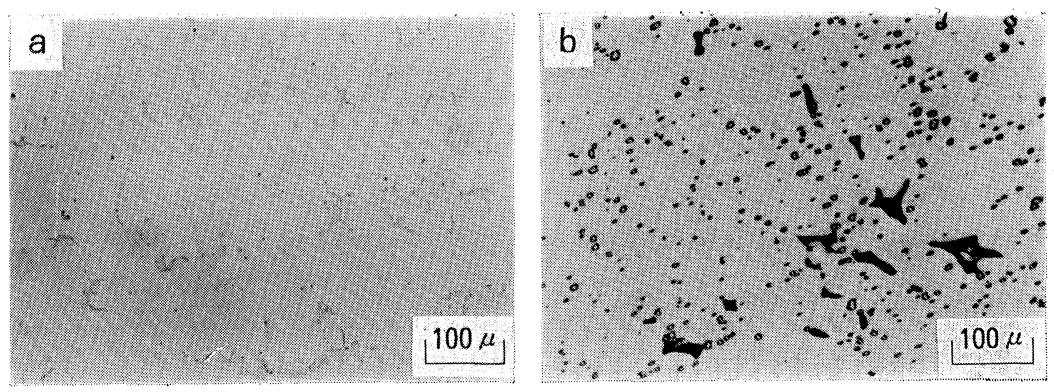
as a die material at around $1050^{\circ} \mathrm{C}$ as far as thermal expansion is concerned.

Physical properties of Nimowal are summarized in Table 5.

\section{Application of Nimowal to Isothermal Forging in Air} In order to develop isothermal forging in air in

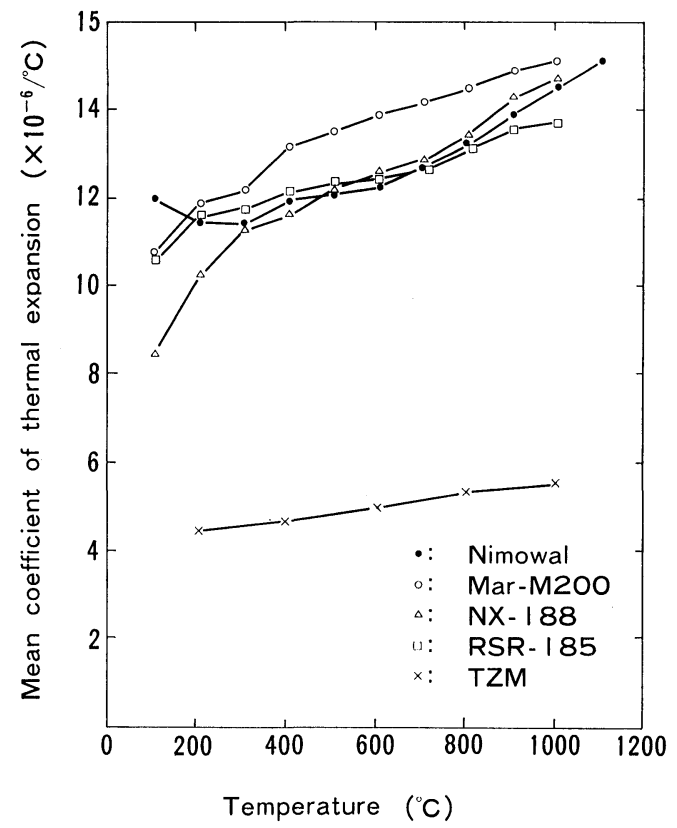

Fig. 12. Mean coefficient of thermal expansion $\left(30^{\circ} \mathrm{C}\right.$ to temp.) of Nimowal, conventional nickel-base superalloys and TZM. which Nimowal is used as the die material, several simulation tests by one-tenth model were made. In these tests, some models were forged without lubricant. For other models, boron nitride (BN) was tried as lubricant. No appreciable reaction between the die and $\mathrm{BN}$ was observed, but the lubricative effect of $\mathrm{BN}$ was not recognized clearly.

For example, Fig. 13 shows the model disk of $1 \mathrm{~N}$ 100 of $26 \mathrm{~mm}$ diameter isothermally forged in air at $1070^{\circ} \mathrm{C}$ with the strain rate of $10^{-3} / \mathrm{s}$ from the extruded billet of $14 \mathrm{~mm}$ diameter and $17 \mathrm{~mm}$ length. The forging was made successfully. No damage of the die was observed. Oxidation of the die was slight enough to be practically used. Thus it was proved that Nimowal can be used for isothermal forging of superalloys in air.

\section{Conclusion}

In order to develop a die material to be used for isothermal forging of superalloys in air, several conventional and experimental nickel-base cast superalloys were investigated. Major results are shown as follows.

(1) Among conventional alloys, special type alloys which contain no chromium showed high strength at above $1000^{\circ} \mathrm{C}$, revealing the possibility to be used as a die material for isothermal forging in air.

(2) Several experimental alloys which contain no chromium were investigated and Nimowal (Ni$10 \mathrm{Mo}-12 \mathrm{~W}-6 \mathrm{Al}-0.01 \mathrm{Y}$ ) showed the best properties as a whole.

(3) Short-time strength of Nimowal is equivalent
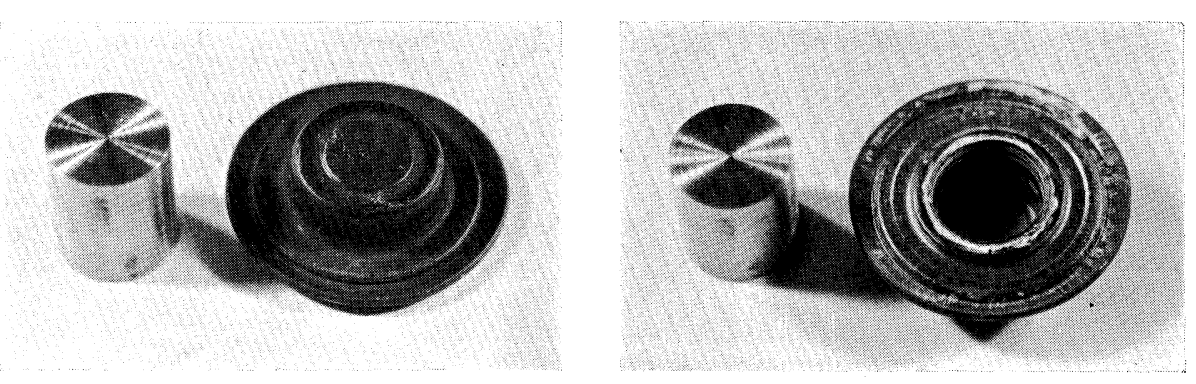

Fig. 13.

One-tenth model disk of IN-100 isothermally forged in air. $(\times 4 / 5)$

Table 5. Physical properties of Nimowal.

1. Density: $8.76 \mathrm{~g} / \mathrm{cm}^{3}$

2. Melting range: $1372 \sim 1413^{\circ} \mathrm{C}$; Solidification range: $1410 \sim 1393^{\circ} \mathrm{C}$

3. Specific heat

\begin{tabular}{lcccccccccccccc} 
Temp. $\left({ }^{\circ} \mathrm{C}\right)$ & 20 & 100 & 200 & 300 & 400 & 500 & 600 & 700 & 800 & 900 & 1000 & 1100 \\
\hline $\mathrm{cal} / \mathrm{g} \cdot{ }^{\circ} \mathrm{C}$ & 0.093 & 0.096 & 0.098 & 0.111 & 0.109 & 0.111 & 0.111 & 0.110 & 0.110 & 0.119 & 0.135 & 0.165 \\
$\mathrm{~J} / \mathrm{kg} \cdot \mathrm{K}$ & 389 & 402 & 410 & 465 & 456 & 465 & 465 & 461 & 461 & 498 & 565 & 691 & \\
\hline
\end{tabular}

4. Thermal conductivity

\begin{tabular}{|c|c|c|c|c|c|c|c|c|c|c|c|c|}
\hline Temp. $\left({ }^{\circ} \mathrm{G}\right)$ & 20 & 100 & 200 & 300 & 400 & 500 & 600 & 700 & 800 & 900 & 1000 & 1100 \\
\hline $\mathrm{cal} / \mathrm{cm} \cdot \mathrm{s} \cdot{ }^{\circ} \mathrm{C}$ & 0.0218 & 0.0224 & 0.0244 & 0.0295 & 0.0318 & 0.0362 & 0.0366 & 0.0394 & 0.0416 & 0.0464 & 0.0534 & 0.0675 \\
\hline $\mathrm{W} / \mathrm{m} \cdot \mathrm{K}$ & 9.1 & 9.4 & 10.2 & 12.4 & 13.3 & 15.2 & 15.3 & 16.5 & 17.4 & 19.4 & 22.4 & 28.3 \\
\hline
\end{tabular}

5. Mean coefficient of thremal expansion $\left(30^{\circ} \mathrm{C}\right.$ to $\mathrm{Temp}$.)

\begin{tabular}{cccccccccccccc}
\hline Temp. $\left({ }^{\circ} \mathrm{C}\right)$ & 100 & 200 & 300 & 400 & 500 & 600 & 700 & 800 & 900 & 1000 & 1100 \\
\hline$\times 10^{-6} /{ }^{\circ} \mathrm{C}$ & 11.98 & 11.47 & 11.41 & 11.94 & 12.11 & 12.29 & 12.79 & 13.27 & 13.97 & 14.62 & 15.21 \\
\hline
\end{tabular}


to that of Mar-M200 at $950 \sim 1000^{\circ} \mathrm{C}$, higher than that of Mar-M200 and equivalent to that of TZM at $1050 \sim 1100^{\circ} \mathrm{C}$.

(4) Compressive creep strength of Nimowal is higher than that of Mar-M200 at $1000 \sim 1100^{\circ} \mathrm{C}$.

(5) Oxidation resistance of Nimowal is equivalent to that of Mar-M200 and enough to be used in air.

(6) Machinability of Nimowal is better than that of Mar-M200.

(7) One-tenth model disk of IN-100 was isothermally forged in air from the extruded billet with the die made of Nimowal without any damage or significant oxidation of the die.

\section{REFERENCES}

1) High Temperature, High Strength Nickel Base Alloys, 3rd ed., The International Nickel Co., Inc., New York, (1977), 4.

2) R. J. Patterson II, A. R. Cox and E. G. van Reuth: J. Metals, 32 (1980), Sep., 34.

3) Aerospace Structural Metals Handbook, V, Metals and Ceramics Information Center, Ohio, (1965), Code 5303.

4) R. W. Burman: J. Metals, 29 (1977), Dec., 12.

5) D. D. Pearson, F. D. Lemkey and B. H. Kear: Proc. of the 4th Int'l Symp. on Superalloys, ASM, Ohio, (1980), 513.

6) K. Ohuch and K. Nakazawa: Japan Soc. Tech. of Plasticity, 26, (1985), 941. 